\title{
Case Report 120
}

R.J. Hernandez, M.D., A.K. Poznanski, M.D.*, J.R. Wesley, M.D., and A.G. Coran, M.D.

Divisions of Pediatric Radiology and Pediatric Surgery, C.S. Mott Children's Hospital, The University of Michigan Medical Center, Ann Arbor, Michigan, USA
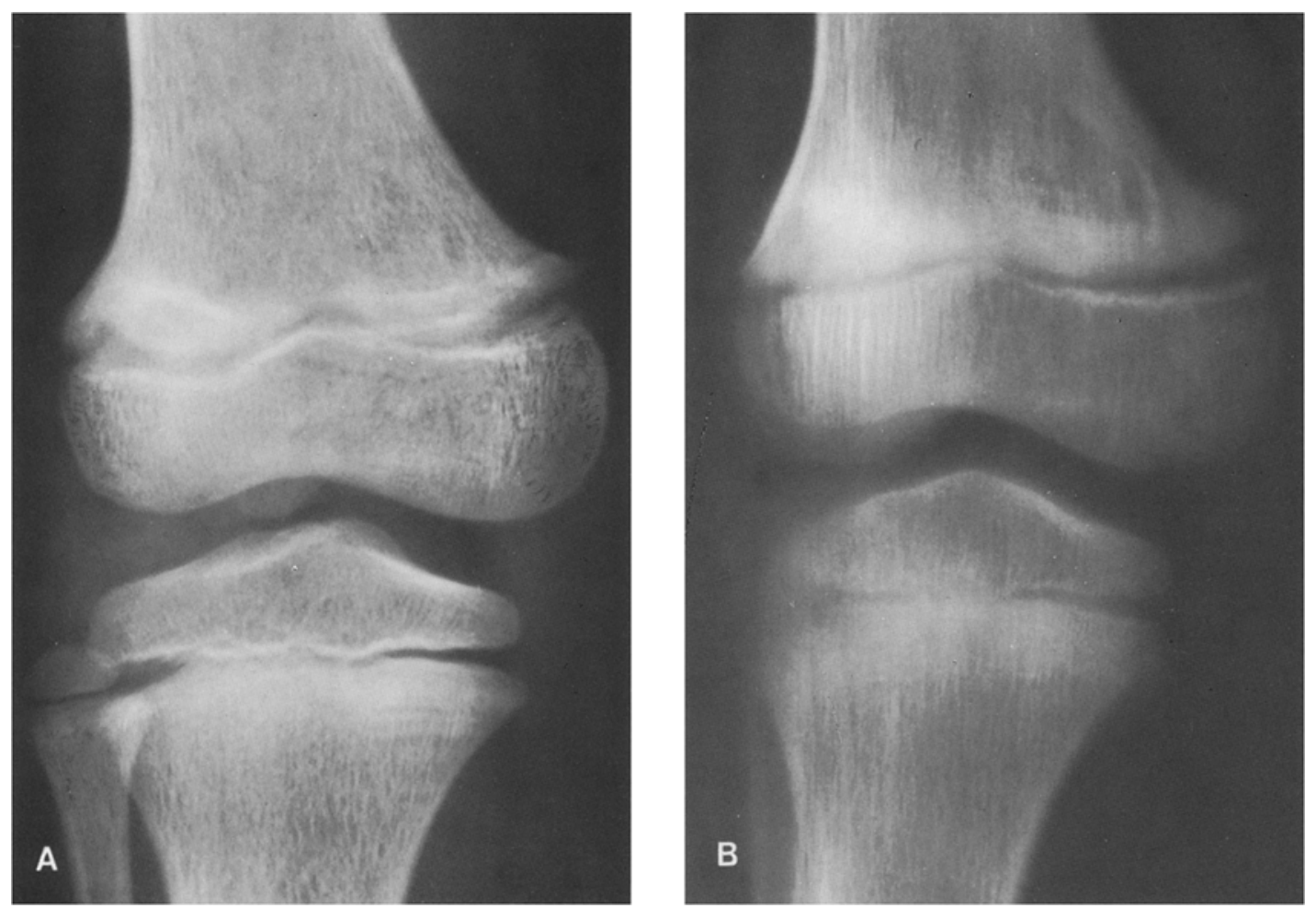

Fig. 1 A and B. A A frontal plane roentgenogram of the right knee shows an area of sclerosis involving the distal femoral metaphysis and suggestively the proximal tibial metaphysis. B A frontal plane laminagram of the right knee again illustrates the areas of bony sclerosis described above

\section{History}

A 6-year-old girl presented with headache. On physical examination papilledema and hypertension $(160 / 120)$ were present. An excretory urogram demonstrated a left suprarenal mass which on ultrasound studies appeared solid and was hypervascular on angiography. The skeletal survey was normal except for the sclerotic areas involving the distal ends of both

\footnotetext{
* Presented by Dr. A.K. Poznanski at the 5th Annual Meeting of the International Skeletal Society in Boston, Massachusetts, September 4-6, 1978
}

femora and each radius and probably the proximal ends of the tibiae (Fig. 1 A and B). A radionuclide scan was normal.

The catecholamine levels in the urine were diagnostic for pheochromocytoma with values six to ten times the normal range.

An operation was performed.

Address correspondence and reprint requests to: A.K. Poznanski, M.D., Department of Radiology, Children's Memorial Hospital, 2300 Children's Plaza, Chicago, IL 60614, USA 


\section{Diagnosis: Probable Bone Infarcts in Long Bones Secondary to Pheochromocytoma}

The differential diagnosis is limited to dense metaphyses necessitating a consideration of either sclerotic metastases (highly unlikely in pheochromocytoma) and infarction of bone.

\section{Discussion}

At operation a large pheochromocytoma was encountered with invasion of the capsular vessels. Follow-up skeletal films on this child obtained 17 months later demonstrated a normal appearance of the affected metaphyses.

Irregular areas of sclerosis and lucencies have been reported in patients with pheochromocytoma and have been attributed to bone infarcts secondary to microcirculatory disturbance. Preoperatively the capillaries in such instances showed slight dilatation. of the arteriolar limb, while the venular limb was markedly dilated and engorged with aggregated red blood cells. Some of the capillaries were thought to contain microthrombi within them. These microcirculatory changes can be explained best by the effects of adrenalin and nor-adrenalin, causing hypovolemia and hemoconcentration in normal man. The pentagastrin-calcium stimulation test for thryocalcitonin was normal in this child. Metastatic pheochromocytoma is unlikely in this patient since such metastases are virtually always lytic in nature and the disappearance of the sclerotic bands in the metaphyses on follow-up films would certainly militate against the posibility of metastatic deposits.

In summary, this brief case report illustrates the concept (although not unequivocally proved) that microcirculatory changes are associated with pheochromocytoma and may produce sclerotic metaphyseal bands in long bones. In this particular instance the transient nature of these sclerotic bands indicates strongly that either vascular insufficiency or actual infarction of bone was present.

\section{References}

1. Becker, M.H., Redisch, W., Messina, E.J.: Bone and microcirculatory changes in a child with benign pheochromocytoma. Radiology 88, 487 (1967)

2. James, R.E., Baker, H.L., Jr., Scanlon, P.W.: The roentgenologic aspects of metastatic pheochromocytoma. Am. J. Roentgenol. 115, 783 (1972) 